it is found that the reaction is bimolecular, showing that the laws of mass action apply to a colloid like gelatin even when in the gel form in which most of the readings were made.

Following up the relation indicated, it was found that two molecules of Sol Form A were in equilibrium with one molecule of Gel, Form B, according to the formula

$$
k(a-x)^{2}=k^{1} x
$$

Considering the change from the Sol Form A to the Gel Form $\mathrm{B}$ as bimolecular and further that a definite amount of the latter forms the standard gel, a formula was derived which permits the calculation of the time necessary for the production of gel in different concentrations at temperatures below $20^{\circ} \mathrm{C}$. $\left(y^{2} d-y b\right)$ $t=$ a constant, where $y$ is the concentration in grams per IOO $\mathrm{cc}$., $d$ the total change in specific rotation observed between $35^{\circ}$ and selected temperature, and $b$ the change necessary to produce the standard gel. Experiment gave satisfactory results in agreement with the formula.

\title{
INFLAMMABILITY OF CARBONACEOUS DUSTS IN AIR AND IN ATMOSPHERES OF LOW OXYGEN CONTENT.
}

\section{By H. H. Brown.}

Severe property losses, in some cases attended by the destruction of human life, have occurred because of the fact that dusts from all materials which will burn are explosive. The Grain Dust Explosion Investigation Laboratory of the Bureau of Chemistry has investigated the explosibility of such dusts, with a view to ascertaining ways to reduce to a minimum the danger from dust explosions and fires in mills, grain elevators and cotton gins.

The relative inflammability of various dusts was determined in the laboratory, using a modification of the method devised by the Bureau of Mines for testing coal dust. Briefly, this method consists in forcing a cloud of dust ( 75 milligrams), which will pass through a 200-mesh screen, against a platinum-covered heating element,. placed in the centre of a round glass globe with a

${ }^{2}$ Brown, H. H.: “Inflammability of Carbonaceous Dusts," J. Ind. Eng. Chem., 9 (I9I7), 269. Brown, H. H., and Clement, J. K.: "Inflammability of Carbonaceous Dusts in Atmospheres of Low Oxygen Content," J. Ind. Eng. Chem., 9 (1917), 347 . 
capacity of approximately I 400 cubic centimeters. The pressure produced by the ignition of the dust was measured by a steam pressure gauge.

The results obtained from a number of tests conducted in this way indicate that the pressure (expressed as pounds per square inch) generated by the ignition of several different types of dust

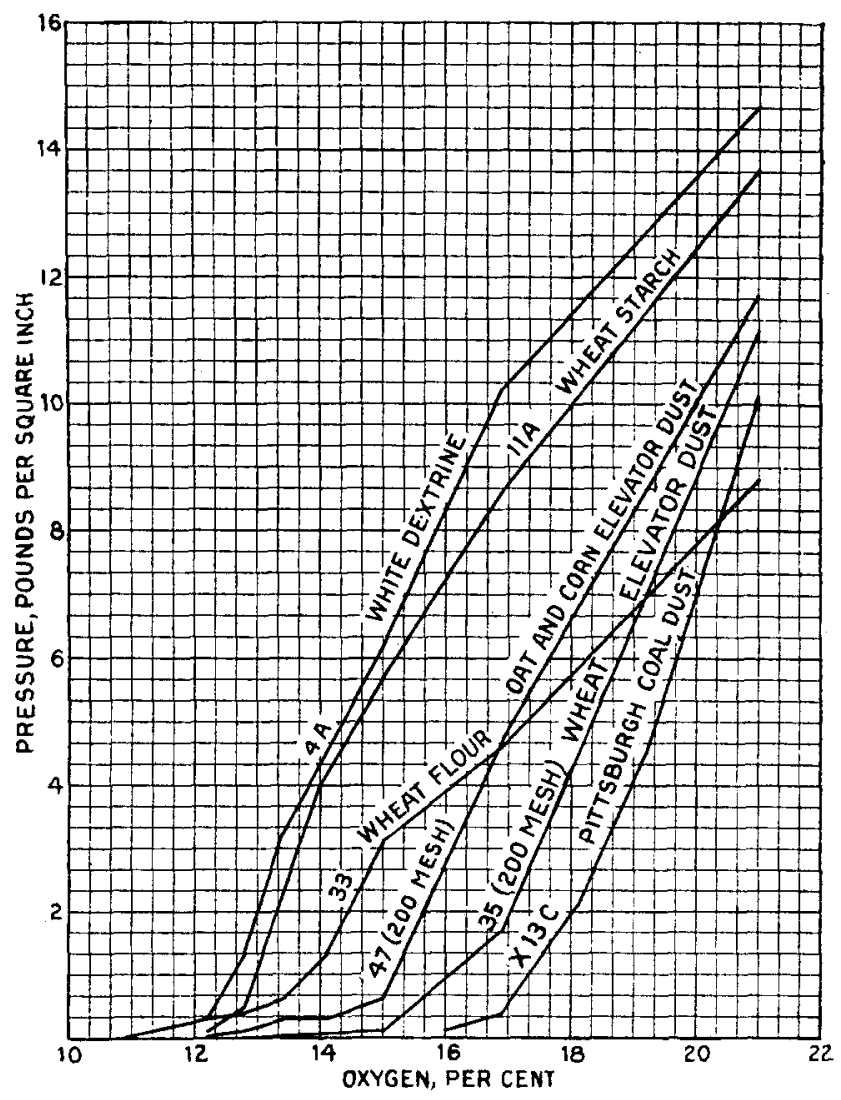

varies from 17.5 in the case of lycopodium and 15.2 for yellow corn dust from the first break in dry milling, through I 3.2 for wheat starch, II.3 for rice starch and IO. I for Pittsburgh standard coal dust, to 3.2 for potato starch and I. I for gelatin dust from an elevator. Obviously, the dusts tested are highly inflammable, so that a cloud of any one of them suspencled in the air forms a dangerous condition. 
In the laboratory tests on the inflammability of coal dust, oxygen was employed to blow the cloud of dust against the heating coil, thus creating an atmosphere containing a greater amount of oxygen than is present in ordinary air. The pressures thus obtained exceed those secured when air alone is used. Conversely, lower pressures are shown when the surrounding air is deficient in oxygen.

A series of experiments was conducted to determine the possibility of employing an inert gas, or one lacking in oxygen, as a means for the prevention of dust explosions in industrial plants. The apparatus used was similar to that already described, with the addition of a device which permitted the filling of the explosion chamber with gas of any desired composition. In this way five typical dusts were tested, using gas mixtures ranging in composition from i6.9 per cent. oxygen, 4 per cent. carbon dioxid, and 79. I per cent. nitrogen to 10.9 per cent. oxygen, 9.2 per cent. carbon dioxid, and 79.9 per cent. nitrogen. The results of this test are clearly shown in the accompanying diagram.

It is evident that an explosion of any of these dusts, which may be regarded as typical carbonaceous dusts of the more inflammable varieties, cannot occur in an atmosphere containing I 2 per cent. or less of oxygen, the rest being inert gases. If elevator dusts alone are considered, this limit is extended to 14 or $14 / 2$ per cent.

Tests conducted on a larger scale, using standard size milling machinery, have shown that it is possible to prevent explosions in these units by means of an atmosphere of inert gas. Results of such tests are now being prepared for publication. 